\title{
Vestibulo-ocular abnormalities in spasmodic torticollis before and after botulinum toxin injections
}

\author{
R STELL, *† A M BRONSTEIN,* C D MARSDEN $\dagger$ \\ From the Medical Research Council Neuro-otology Unit* and the University Department of Clinical \\ Neurology, $\dagger$ Institute of Neurology, National Hospital for Nervous Diseases, London, UK
}

SUMMARY In order to establish whether vestibular abnormalities often found in spasmodic torticollis are secondary to the abnormal head posture, the vestibulo-ocular reflex (VOR) was studied in eight patients before and after correction of head posture with botulinum toxin. Eye movements were recorded in the dark during sinusoidal and velocity step rotation. Four patients showed a significantly asymmetric response, with the slow phase of the VOR more active ipsilateral to the torticollis (chin). Despite significant improvement of the head posture in all patients for up to 10 weeks following treatment, no correction of the vestibular asymmetry occurred. This suggests that the VOR abnormalities are not caused by the head posture itself. We interpret the findings as evidence of primary involvement of the vestibular system in torticollis and we postulate a widespread derangement of the sensory-motor mechanisms controlling head posture in this disease.

Spasmodic torticollis (ST) is a focal dystonia characterised by involuntary movements and postures of the head consisting of either horizontal rotation or tilt in the sagital or coronal planes, or any combination of the above. No convincing pathology has been demonstrated, ${ }^{1-3}$ but it may be that torticollis, like other forms of dystonia, is due to a functional abnormality of neurotransmitter action in the basal ganglia. ${ }^{4}$

The condition has long been thought to be associated with abnormalities of vestibular function. Indeed some authors have used techniques to suppress vestibular function as a method of treatment. ${ }^{6}$ Central and peripheral lesions of the vestibular system and its projections are known to cause abnormal head postures, although in humans this is exceptional..$^{7-9}$ In a review of 35 patients with ST studied in our vestibular laboratory, about $70 \%$ had a directional preponderance of caloric/rotational nystagmus contralateral to the side to which the chin pointed. ${ }^{10}$ More recently, measurements of ocular counter-rolling evoked at low frequency rotation have suggested abnormalities of otolith function in patients with spasmodic torticollis. ${ }^{11}$ However, the significance of these vestibular abnormalities is uncertain. In particular, it is not clear

Address for reprint requests: Dr Adolfo M Bronstein, MRC Neurootology Unit, Institute of Neurology, National Hospital for Nervous Diseases, Queen Square, London WCIN 3BG, UK.

Received 24 June 1988 and in revised form 16 August 1988. Accepted 6 September 1988 whether they are a reflection of an underlying abnormality responsible for the torticollis, or whether they are secondary to the abnormal head posture.

The recent development of botulinum toxin ${ }^{1213}$ to treat such patients has allowed us to investigate this problem further by analysing vestibular function before and after the correction of the abnormal head posture.

\section{Patients and methods}

Eight patients with isolated spasmodic torticollis causing predominant horizontal rotation of the head were studied (table 1). Patients with this particular head posture were selected because the function of the horizontal semicircular

Table 1 Patient characteristics

\begin{tabular}{|c|c|c|c|c|c|c|}
\hline \multirow[b]{2}{*}{$\begin{array}{l}\text { Patient } \\
\text { No. }\end{array}$} & \multirow[b]{2}{*}{ Sex } & \multirow[b]{2}{*}{$\begin{array}{l}\text { Age } \\
(y r)\end{array}$} & \multirow[b]{2}{*}{$\begin{array}{l}\text { Disease } \\
\text { duration } \\
\text { (yr) }\end{array}$} & \multirow[b]{2}{*}{$\begin{array}{l}\text { Pre- } \\
\text { treatment }\end{array}$} & \multicolumn{2}{|l|}{ Torticollis* } \\
\hline & & & & & $\begin{array}{l}3 \text { weeks } \\
\text { after botuli }\end{array}$ & $\begin{array}{l}10 \text { weeks } \\
\text { linum toxin }\end{array}$ \\
\hline $\begin{array}{l}1 \\
2 \\
3 \\
4 \\
5 \\
6 \\
7 \\
8\end{array}$ & $\begin{array}{l}\mathbf{M} \\
\mathbf{M} \\
\mathbf{M} \\
\mathbf{F} \\
\mathbf{F} \\
\mathbf{M} \\
\mathbf{F} \\
\mathbf{F}\end{array}$ & $\begin{array}{l}35 \\
40 \\
42 \\
31 \\
53 \\
56 \\
47 \\
59\end{array}$ & $\begin{array}{r}6 \\
12 \\
5 \\
8 \\
22 \\
20 \\
8 \\
3\end{array}$ & $\begin{array}{l}15^{\circ} \mathrm{L} \\
35^{\circ} \mathrm{L} \\
50^{\circ} \mathrm{L} \\
60^{\circ} \mathrm{L} \\
40^{\circ} \mathrm{L} \\
30^{\circ} \mathrm{L} \\
50^{\circ} \mathrm{R} \\
70^{\circ} \mathrm{L}\end{array}$ & $\begin{array}{c}5^{\circ} \mathrm{L} \\
25^{\circ} \mathrm{L} \\
35^{\circ} \mathrm{L} \\
35^{\circ} \mathrm{L} \\
10^{\circ} \mathrm{L} \\
20^{\circ} \mathrm{L} \\
30^{\circ} \mathrm{R} \\
0^{\circ}\end{array}$ & $\begin{array}{c}0^{\circ} \\
25^{\circ} \mathrm{L} \\
25^{\circ} \mathrm{L} \\
15^{\circ} \mathrm{L} \\
15^{\circ} \mathrm{L} \\
20^{\circ} \mathrm{L} \\
15^{\circ} \mathrm{R} \\
20^{\circ} \mathrm{L}\end{array}$ \\
\hline
\end{tabular}

-The degree of deviation of the chin (in degrees), either to the right $(R)$ or left $(L)$, in the horizontal plane is shown before, and 3 and 10 weeks after injection of botulinum toxin. 
canals is routinely examined by caloric and rotational testing. Apart from the torticollis, no patient had other abnormalities on routine neurological and clinical oto-neuro-ophthalmological examination. There were four females and four males, with a mean age of 44 years (range 31-59). Mean disease duration was 9.5 years (range 3-22). Seven patients had rotation of the chin to the left and one to the right. Medications were continued as long as they had not been commenced within two months of the study.

All patients had the angle of head rotation and/or tilt measured with a protractor. Eye movements were recorded with bitemporal DC electronystagmography (ENG) on to paper with an ink-jet polygraph (Mingograph). The patient's head was restrained as straight as possible using binaural head clamps and an occipital head rest, whilst sitting on a motorised revolving chair. Chair (head) motion was transduced by a tachometer. Recordings were measured by hand.
The vestibular stimulus consisted of sinusoidal rotation in the dark at a frequency of $0.3 \mathrm{~Hz}$ and peak velocity of $50^{\circ} / \mathrm{s}$. Slow phase velocity of nystagmus during sinusoidal rotation was measured and at least six slow phases in each direction were averaged to calculate the gain of the vestibulo-ocular reflex (VOR), defined as the ratio of peak eye velocity to peak head velocity. A qualitative observation of the phase of the VOR was made according to whether the reversal of the direction of the slow component preceded or followed the reversal of chair direction; this was then expressed as either a phase lead or lag respectively. In addition, a velocity step of $+/-40 \%$ in the dark was delivered, and the peak velocity and the time constant of the slow component of nystagmus were measured. Time constant was defined as the time taken by the initial peak eye velocity to drop by $63 \%$.

All patients received botulinum toxin in a dosage of 500 mouse units to each of the two most active muscles selected

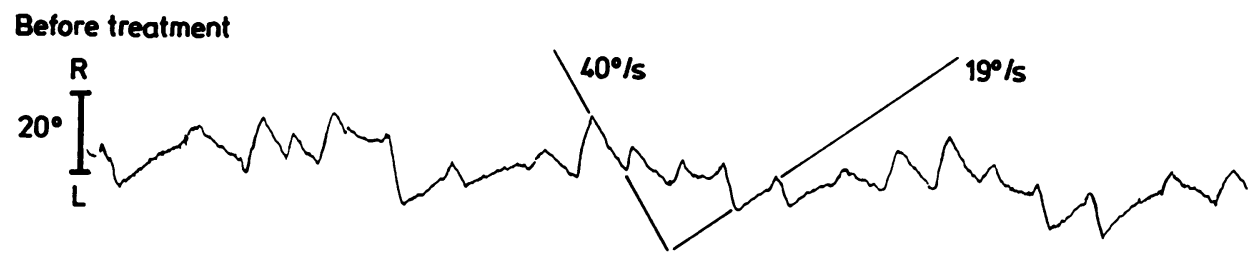

3 weeks after treatment
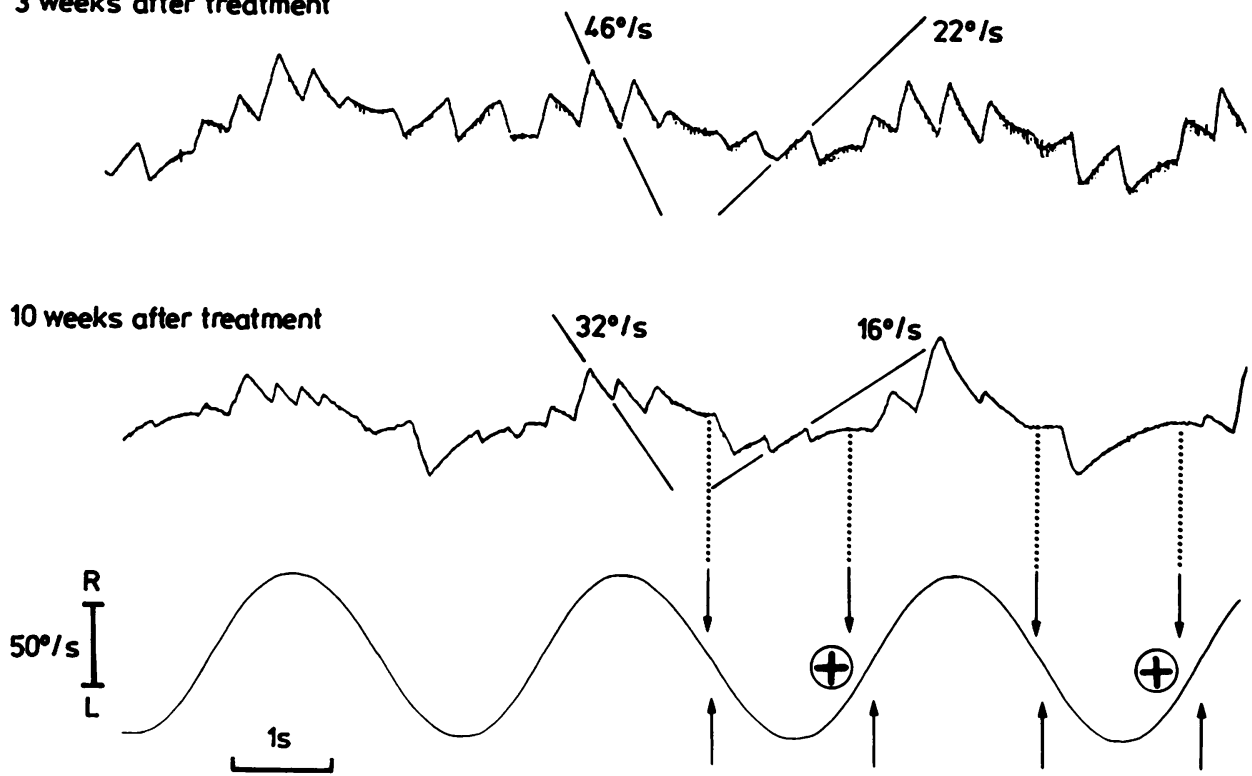

Fig 1 Eye movements elicited by sinusoidal rotation in the dark in patient with torticollis (chin to the left) before, and 3 and 10 weeks after correction of head posture with botulinum toxin. Slow phase velocities to the left (that is, during nystagmus to the right), are greater than in the opposite direction in all instances. Bottom right: the upward arrows indicate the zero velocity points on the chair velocity trace (at the time of peak chair displacement), and the downward arrows indicate the points where the slow phase eye movements reverse direction. The + sign indicates a phase lead of the change in direction of the slow phase of the induced vestibular nystagmus with respect to peak chair displacement during leftward rotation. 
either clinically or on EMG using a technique described previously by us. ${ }^{13}$ The patients were studied just prior to injection, and again at 3 weeks and approximately 10 weeks post-injection. Twenty normal subjects (age range 20-61 years) underwent sinusoidal rotation and 13 of these also underwent step rotation as above, for comparison.

\section{Results}

Figure 1 shows raw ENG records of patient 8 during sinusoidal rotation pre and post-treatment. This patient's head rotation was $70^{\circ}$ to the left pre-treatment, and $0^{\circ}$ and $20^{\circ}$ to the left at 3 and 10 weeks respectively. On rotation of the chair to the right the slow phase velocity of the induced nystagmus persistently exceeded the velocity of the nystagmus induced by rotation to the left. There was no alteration in this asymmetry in the nystagmic response following treatment.

The results of sinusoidal rotation for all patients are summarised in table 2 . For all patients with torticollis, the mean pre-treatment VOR gain (right and left combined) was 0.73 (SD 0.17), and the control value was 0.66 (SD 0.16); no patient lay outside 2 standard deviations from the mean of the normal subjects.

In order to assess the significance of the asymmetries found, the formula:

(VOR gain to the right - VOR gain to the left) $\times 100$

(VOR gain to the right + VOR gain to the left)

was applied to the pre-treatment data. This calculation is frequently applied in neuro-otological practice to quantify asymmetries of vestibular function. ${ }^{14}$ Confidence limits were set at two standard deviations from the mean of the normal population. The control group had a mean value of $3.94 \%$ (SD 3.34). Five patients (cases $1,2,3,6,8)$ had an asymmetry of VOR gain with the more active nystagmus contralateral to the direction of the torticollis (chin), but this was within the confidence limits in patient 1 . Three patients $(4,5,7)$ had a more active response ipsilateral to the torticollis

Table 2 VOR gain (to right $-R$, or left $-L$ ) during sinusoidal rotation before, and 3 and 10 weeks after treatment with botulinum toxin

\begin{tabular}{|c|c|c|c|c|c|c|c|}
\hline \multirow{2}{*}{$\begin{array}{l}\text { Patient } \\
\text { No. }\end{array}$} & \multirow{2}{*}{$\begin{array}{l}\text { Torti- } \\
\text { collis }\end{array}$} & \multicolumn{2}{|c|}{ Pre-treatment } & \multicolumn{2}{|c|}{3 weeks } & \multicolumn{2}{|c|}{10 weeks } \\
\hline & & $\boldsymbol{R}$ & $L$ & $\boldsymbol{R}$ & $L$ & $\boldsymbol{R}$ & $L$ \\
\hline $\begin{array}{l}1 \\
2 \\
3 \\
4 \\
5 \\
6 \\
7 \\
8\end{array}$ & $\begin{array}{l}\mathbf{L} \\
\mathbf{L} \\
\mathbf{L} \\
\mathbf{L} \\
\mathbf{L} \\
\mathbf{L} \\
\mathbf{R} \\
\mathbf{L}\end{array}$ & $\begin{array}{l}0.97 \\
1.04 \\
0.51 \\
0.75 \\
1.00 \\
0.82 \\
0.59 \\
1.01\end{array}$ & $\begin{array}{l}0.73 \\
0.55 \\
0.39 \\
0.85 \\
1.05 \\
0.59 \\
0.53 \\
0.61\end{array}$ & $\begin{array}{l}0.27 \\
1.28 \\
0.54 \\
0.76 \\
0.83 \\
0.82 \\
0.78 \\
1.08\end{array}$ & $\begin{array}{l}0.23 \\
0.69 \\
0.36 \\
1.06 \\
0.94 \\
0.53 \\
0.66 \\
0.68\end{array}$ & $\begin{array}{l}0.40 \\
0.80 \\
0.36 \\
0.62 \\
0.68 \\
0.55 \\
0.86 \\
0.68\end{array}$ & $\begin{array}{l}0.30 \\
0.54 \\
0.26 \\
0.80 \\
0.80 \\
0.34 \\
0.76 \\
0.56\end{array}$ \\
\hline
\end{tabular}

but in none of these was it significant. There was no clinical difference between these subgroups of patients. In all patients with a significant VOR gain asymmetry a phase lead for the slow phase of the vestibular nystagmus was found during chair rotation in the direction of the lower gain (see figure 1, bottom right), the net result being a prolongation of the duration of the nystagmus in the direction of the higher VOR gain.

Figure 2 summarises the change in head posture and figure 3 the asymmetry in VOR gain following botulinum toxin injection in all patients. For graphic purposes VOR symmetry is presented as the ratio between VOR gain ipsilateral divided by VOR gain contralateral to chin deviation, so that cases with VOR more active in the same-opposite direction of the torticollis are clearly identified. Arbitrarily, in the normal control group right VOR gain was divided by left VOR gain.

It can be seen that a considerable improvement of head posture was achieved in all patients but, despite this, the VOR asymmetry persisted essentially unchanged. A paired Student's $t$ test confirmed that changes in head posture between pre and 3 weeks post treatment were statistically significant $(t=4.89$; $\mathrm{p}<0.01)$ whereas changes in VOR asymmetry were not $(t=1.43 ; \mathrm{p}>0.05)$. Patient 7 increased the degree of VOR asymmetry (more active ipsilateral to the torticollis) post-injection despite the improvement in head posture.

The results of the velocity step rotational test are shown in table 3. These were in general agreement with those of the sinusoidal test. The mean slow phase velocity (right and left combined) for control subjects was $32.04^{\circ}$ s (SD 8.01) and for the patients was $26.45^{\circ} / \mathrm{s}$ (SD 5.86). There was no statistical difference between these values $(t=1.68 ; \mathrm{p}>0.05)$. The mean time constant (tc) for control subjects was 13.35 (SD 4.45) and for patients 14.98 (SD 2.34); this difference was not significant $(t=0.95 ; \mathrm{p}>0.05)$. The formula used above to assess the significance of VOR asymmetry was applied to peak slow phase velocity of nystagmus. ${ }^{14}$ The control group had a mean value of $2.00 \%$ (range- $7 \cdot 32$ to $15 \cdot 22$ ). Six patients (cases 1,2 , $3,4,6,8)$ had an asymmetry of the step rotational response with the more active nystagmus contralateral to the direction of the torticollis; in 3 of these (cases 3 , $4,8)$ the values lay outside the normal range. Two patients (cases 5,7 ) had slightly more active nystagmus ipsilateral to the torticollis but in both of these it lay within the normal range. In three patients (cases 2, 3, 8) there was a considerable asymmetry of the time constant and in these cases it was shorter with rotation in the direction of the lower VOR gain and peak slow phase velocity of nystagmus. There was no significant change in the symmetry of peak velocity $(t=0.47$; $\mathrm{p}>0.05)$ and time constant $(t=1.77 ; \mathrm{p}>0.05)$ of 


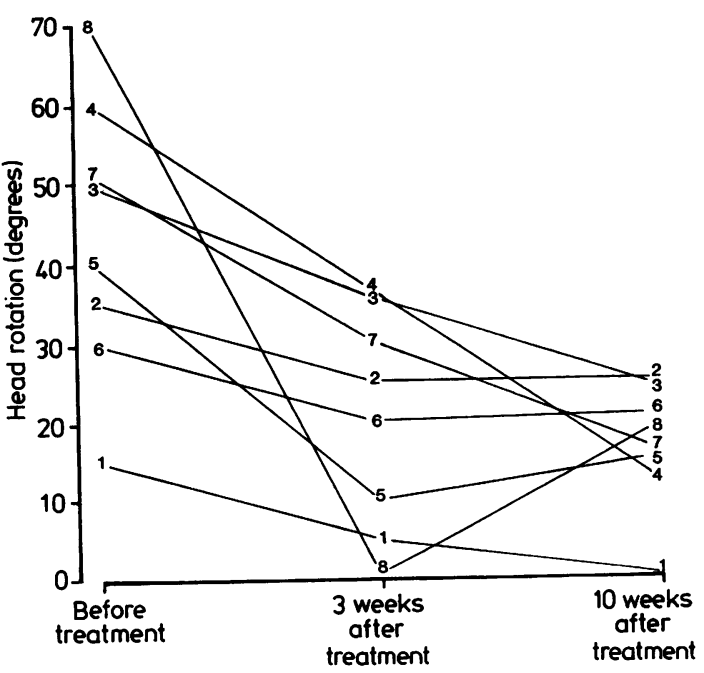

Fig 2 Head position due to torticollis (horizontal rotation in degrees) before, and 3 and 10 weeks after botulinum toxin treatment. The numbers identify the individual patients as in table 1.

vestibular nystagmus before and after treatment.

Two further patients were studied during the collection of the above data. One a 34 year old man with pure retrocollis $\left(20^{\circ}\right)$ and the second a 49 year old woman with pure laterocollis $\left(10^{\circ}\right)$. In both normalisation of head position was achieved following botulinum toxin. In neither was there a significant asymmetry of either VOR gain or peak slow phase velocity of induced nystagmus.

\section{Discussion}

This study confirms previous reports of abnormal vestibular function in some patients with spasmodic torticollis. ${ }^{111}$ Four out of the eight patients with predominantly rotational torticollis had a significant

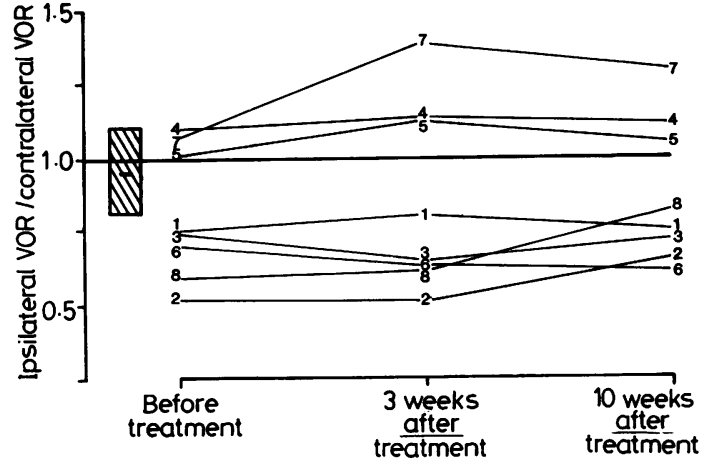

Fig 3 Symmetry of the VOR during sinusoidal rotation before and 3 and 10 weeks after botulinum toxin, assessed as the ratio between VOR gain ipsilateral to the toricollis and $V O R$ gain contralateral to the torticollis. Cases with a value $<1$ have a VOR more active during rotation in the direction opposite to the chin deviation due to the torticollis. The hatched area represents mean (2SD) of the normal controls after dividing VOR gain to the right by VOR gain to the left. The numbers identify the individual patients as in table 1.

asymmetry of the VOR, with the more active nystag- $\square$ mus occurring in the direction opposite to that of chin 0 . deviation. There was good agreement between the $\stackrel{\odot}{\Phi}$ 음 various parameters measured during testing; a higher $\stackrel{\mathbb{\Omega}}{\mathbb{Q}}-$ VOR gain in one direction during sinusoidal rotation usually was accompanied by a phase lead in the opposite direction. In addition, during the velocity step, there was a greater peak slow component velocity with a longer time constant contralateral to the torticollis. These results provide further quantitative support to our previous clinical review of patients with ST, of whom approximately $70 \%$ showed a directional preponderance of vestibular nystagmus (measured as duration of the response) in the direction opposite to the torticollis. ${ }^{10}$ Since the direction of nystagmus is by convention in the direction of the quick component, the slow component of the VOR is therefore more

Table 3 Peak velocity (PV) $(\%$ ) and time constant $(T C)(s)$ of nystagmus during velocity step rotation, before and 3 and 10 weeks after treatment with botulinum toxin

\begin{tabular}{|c|c|c|c|c|c|c|c|c|c|c|c|c|c|}
\hline \multirow{3}{*}{$\begin{array}{l}\text { Patient } \\
\text { No. }\end{array}$} & \multirow[b]{3}{*}{ Torticollis } & \multicolumn{4}{|c|}{ Pre-treatment } & \multicolumn{4}{|c|}{3 Weeks } & \multicolumn{4}{|c|}{10 Weeks } \\
\hline & & \multicolumn{2}{|c|}{$(P V)$} & \multicolumn{2}{|c|}{$(T C)$} & \multicolumn{2}{|c|}{$(P V)$} & \multicolumn{2}{|c|}{$(T C)$} & \multicolumn{2}{|c|}{$(P V)$} & \multicolumn{2}{|l|}{$(T C)$} \\
\hline & & $R$ & $L$ & $R$ & $L$ & $R$ & $L$ & $R$ & $L$ & $R$ & $L$ & $\boldsymbol{R}$ & $L$ \\
\hline $\begin{array}{l}1 \\
2 \\
3 \\
4 \\
5 \\
6 \\
7 \\
8\end{array}$ & $\begin{array}{l}\mathbf{L} \\
\mathbf{L} \\
\mathbf{L} \\
\mathbf{L} \\
\mathbf{L} \\
\mathbf{L} \\
\mathbf{R} \\
\mathbf{L}\end{array}$ & $\begin{array}{l}33.5 \\
37.5 \\
23.0 \\
29.5 \\
33.0 \\
31.0 \\
23.0 \\
28.0\end{array}$ & $\begin{array}{l}27.5 \\
30.0 \\
16.5 \\
21.5 \\
35.0 \\
25.0 \\
21.5 \\
18.0\end{array}$ & $\begin{array}{l}13.5 \\
20.0 \\
16.5 \\
13.5 \\
20.0 \\
17.5 \\
17.0 \\
20.5\end{array}$ & $\begin{array}{r}12.5 \\
10.5 \\
11.0 \\
10.0 \\
18.0 \\
15.0 \\
16.7 \\
7.5\end{array}$ & $\begin{array}{l}53 \cdot 5 \\
49 \cdot 5 \\
45 \cdot 5 \\
38 \cdot 0 \\
42 \cdot 0 \\
35 \cdot 5 \\
63 \cdot 5 \\
25 \cdot 0\end{array}$ & $\begin{array}{l}40.5 \\
39.0 \\
37.5 \\
55.0 \\
37.0 \\
30.5 \\
59.0 \\
22.0\end{array}$ & $\begin{array}{l}14.5 \\
18.0 \\
18.0 \\
17.0 \\
17.5 \\
16.5 \\
12.0 \\
15.0\end{array}$ & $\begin{array}{l}14.0 \\
10.5 \\
12.5 \\
20.0 \\
22.0 \\
12.0 \\
65.0 \\
11.5\end{array}$ & $\begin{array}{l}23 \cdot 0 \\
45 \cdot 0 \\
28 \cdot 0 \\
27 \cdot 0 \\
32 \cdot 0 \\
17 \cdot 0 \\
36 \cdot 0 \\
20 \cdot 5\end{array}$ & $\begin{array}{r}16 \cdot 5 \\
40.0 \\
20.0 \\
38.5 \\
34.0 \\
12.5 \\
32.0 \\
7.5\end{array}$ & $\begin{array}{r}9.8 \\
16.0 \\
20.0 \\
9.5 \\
23.5 \\
19.0 \\
17.5 \\
30.0\end{array}$ & $\begin{array}{r}8.0 \\
10.0 \\
22.5 \\
14.5 \\
23.0 \\
12.5 \\
23.0 \\
27.0\end{array}$ \\
\hline
\end{tabular}


active ipsilateral to the direction of the torticollis (defined by the deviation of the chin). As the slow component of the VOR is generated by the vestibular system, this indicates that in ST there may be a tonic bias of neural activity affecting cervical muscles and vestibulo-ocular balance in the same direction.

Following botulinum toxin injection, improvement in head posture was achieved in all patients. This benefit reached its maximum one week after injection and remained relatively stable until the patients were restudied 10 weeks later. Despite this sustained improvement in head posture, there was no change in the VOR asymmetry evident in either the sinusoidal or step rotational test, suggesting that the abnormal VOR is not secondary to the head posture per se. This conclusion is also supported by the following evidence, (1) in normal subjects, voluntary forced head rotation has no consistent effect on the symmetry of the VOR $;{ }^{15}$ however, acute voluntary head rotation is not strictly analogous to chronic involuntary torticollis, (2) all patients were studied with their heads held in an almost neutral position, particularly after botulinum toxin treatment, which considerably facilitated adequate head positioning in the rotating chair, (3) recordings of the cervico-ocular reflex in ST patients suggests that an abnormal input from the neck proprioceptors onto the vestibular nuclei cannot be held responsible for the asymmetric VOR described. ${ }^{16}$ We conclude that these asymmetric vestibular responses may be directly related to the underlying disorder producing the abnormal head posture in spasmodic torticollis.

There are at least two ways in which spasmodic torticollis and the vestibular system may relate to each other. First, it has been postulated that the torticollis may be due to hyperactive, disinhibited or perverted vestibulo-collic reflexes (VCR), which normally are responsible in animals for stabilising the head in space. Suggestive evidence for this conclusion was provided by Denny-Brown, ${ }^{17}$ who described patients in whom the severity of their torticollis was significantly modulated when turning. However, a difficulty with this line of argument is that the influence of the vestibulo-collic reflex upon head posture diminishes as one ascends the phylogenetic scale. Indeed, the existence of the VCR in man has been questioned. ${ }^{18}$ Although recent work indicates that vestibular signals do contribute to some extent to head stability in normal subjects, ${ }^{19-21}$ it seems that hyperreactivity of the VCR in patients with torticollis does not occur; ${ }^{22} 23$ whilst neck EMG activity during rotation at constant angular acceleration was shown to modulate in a proportion of patients, this was not of a magnitude sufficient to indicate a casual relationship between VCR and torticollis. ${ }^{22}$ Similarly, an analysis of head movements evoked by random whole body oscillation has not provided evidence for a major effect of the VCR in these patients. ${ }^{23}$ The fact that the mean VOR gain of our patients was essentially equivalent to that of the normal control group also argues against hyperexcitable vestibular responses. Accordingly, it could be suggested that modulation of the torticollis on turning, noted in some patients, may represent the response to a specific motor act rather than to the vestibular stimulus itself.

A second possibility is that the VOR abnormalities in spasmodic torticollis are a consequence of a more generalised disruption of the mechanisms controlling head posture and movement. Such a process would be expected to involve not only vestibular mechanisms, but also the processing of other sensori-motor signals relevant to head position, which might explain the commonly associated finding in spasmodic torticollis of exaggerated responses to somato-sensory cues. ${ }^{174}$ This probably underlies the mechanism of the "antagonistic gesture" used by many patients to improve their head posture. Further support for a more diffuse disorder is the finding of abnormal brain stem reflexes, for example blink reflexes ${ }^{25}$ in some patients with ST. These abnormalities may be explained by malfunction of reticular polysynaptic interneuronal pathways. ${ }^{26}$ The intimate relationship between the reticular formation and the vestibular system is well known; ${ }^{27}$ for example, most eye movement related neurons in the reticular formation are known to send descending branches which influence the cervical musculature coordinating head and eye motion ${ }^{29}$ and, reciprocally, descending vestibular signals significantly influence reticulo-spinal pathways. ${ }^{27}$ Of particular relevance are animal studies in which selected reticular nuclei have been lesioned to produce experimental torticollis and tonic eye deviation. ${ }^{30-33}$ The most notable of these reticular nuclei is the interstitial nucleus of Cajal, which has bidirectional connections both with the vestibular nuclei and the basal ganglia. Unfortunately, detailed vestibular tests of animals with lesion-induced torticollis have not been reported, so that at present the relevance to human disease is not clear. Diseases affecting the basal ganglia in man are known to produce dystonia, and could do so via the projections to structures such as the interstitial nucleus of Cajal.

In conclusion, this study confirms the presence of vestibulo-ocular abnormalities in a considerable proportion of patients with idiopathic spasmodic torticollis. These abnormalities consist of a VOR asymmetry, with the more active slow component being ipsilateral to the direction of the torticollis. This abnormality dose not appear to be secondary to the abnormal head position, since correction of the latter with botulinum toxin does not alter the degree of asymmetry. Current data do not support the thesis 
that a disinhibited vestibulo-collic reflex is responsible for torticollis, so we postulate a more widespread central derangement of the various mechanisms controlling head posture.

Dr R Stell acknowledges the help of the Dystonia Medical Research Foundation for financial support.

\section{References}

1 Tarlov VE. On the problem of the pathology of spasmodic torticollis in man. J Neurol Neurosurg Psychiatry 1970;33: 457-63.

2 Zeeman W, Dyken P. Dystonia Musculorum Deformans. In: Vinken PJ, Bruyn GW, eds. Handbook of Neurology Vol 6. 1968:517-43.

3 Garcia-Albea E, Franch O, Munoz D, Ricay JR. Breughel's Syndrome: report of a case with post-mortem studies. $J$ Neurol Neurosurg Psychiatry 1981;44:437-40.

4 Rothwell JC, Obeso JA. The anatomical and physiological basis of torsion dystonia. In: Marsden CD, Fahn S, eds. Movement Disorders 2. London: Butterworths, 1987:313-31.

5 Barre JA. Le Torticollis Spasmodique. Rev Neurol (Paris) 1929;(I):984-1013.

6 Svien HJ, Cody DTR. Treatment of spasmodic torticollis by suppression of labyrinthine activity. Report of a case. Mayo Clin Proc 1969;44:825-7.

7 Brain WR. On the rotated or "cerebellar" posture of the head. Brain 1929;49:61-76.

8 Halmagyi GM, Gresty MA, Gibson WPR. Ocular tilt reaction with peripheral vestibular lesions. Ann Neurol 1978;6:80-83.

9 Magnus R. Korperstellung. Berlin: Springer, 1924.

10 Bronstein AM, Rudge P. Vestibular involvement in spasmodic torticollis. J Neurol Neurosurg Psychiatry 1986;49:290-5.

11 Diamond SG, Markham CH, Baloh RW. Ocular counter-rolling abnormalities in spasmodic torticollis. Arch Neurol 1988;45: $164-9$.

12 Tsui JK, Eisen A, Stoessl A, Calne S, Calne DB. Double-blind study of botulinum toxin in spasmodic torticollis. Lancet 1986;ii:245-6.

13 Stell R, Thompson PD, Marsden CD. Botulinum toxin in spasmodic torticollis. J Neurol Neurosurg Psychiatry 1988;51: 920-3.

14 Baloh RW, Honrubia V. Clinical Neurophysiology of the Vestibular System. Philadelphia: FA Davis, 1979.

15 Bronstein AM, Hood JD. The cervico-ocular reflex in normal subjects and patients with absent vestibular function. Brain Res 1986;373:399-408.

16 Bronstein AM, Rudge P. The vestibular system in abnormal head postures and in spasmodic torticollis. In: Fahn S, Marsden CD,
Calne DB. Advances in Neurology Vol 50, Dystonia 2. New York: Raven Press, 1988:493-500.

17 Denny-Brown D. Clinical symptomatology of diseases of the basal ganglia. In: Vinken PJ, Bruyn GW, eds. Handbook of Neurology. Vol 6. 1968;133-72.

18 Barnes GR, Rance BH. Transmission of angular acceleration to the head in the seated human subject. Aerospace Med 1974;45:411-6.

19 Outerbridge JS, Melville Jones G. Reflex vestibular control of head movement in man. Aerospace Med 1971;42(9):935-40.

20 Guitton D, Kearney RE, Wereley N, Peterson BW. Visual vestibular and voluntary contributions to human head stabilization. Exp Brain Res 1986;64:59-69.

21 Bronstein AM. Evidence for a vestibular input contributing to dynamic head stabilization in man. Acta Otolaryngol (Stockh). 1988;105:1-6.

22 Bronstein AM, Rudge P, Beechey AH. Spasmodic torticollis following VIII nerve lesions: neck EMG modulation in response to vestibular stimuli. J Neurol Neurosurg Psychiatry 1987; 50:580-6.

23 Gresty M. Stability of the head: Studies in normal subjects and in patients with labyrinthine disease, head tremor and dystonia. Movement Disorders 1987;2:165-85.

24 Podivinsky F. Torticollis. In: Vinken PJ, Bruyn GW, eds. Handbook of Neurology Vol 6. 1968:567-603.

25 Tolosa ES, Montserrat L. Depressed blink reflex habituation in dystonic blepharospasm. Neurology 1985;35(Suppl):271.

26 Tolosa ES, Montserrat L, Bayes A. Blink reflex studies in focal dystonias: Enhanced excitability of brain stem interneurons in cranial dystonia and spasmodic torticollis. Movement Disorders 1988;3:61-69.

27 Fukushima K, Peterson BW, Wilson VJ. Vestibulospinal, Reticuospinal and Interstitiospinal pathways in the cat. In: Granit R, Pompeiano O, eds. Progress in Brain Research Vol 50. Amsterdam: Elsevier/North-Holland Biomedical Press, 1979:121-36.

28 Wilson VJ, Melville Jones G. Mammalian Vestibular Physiology. New York: Plenum Press, 1979.

29 Buttner-Ennever J, Holstege G. Anatomy of premotor centres in the reticular formation controlling oculomotor skeletomotor and autonomic motor systems. In: Freund $\mathrm{HJ}$, Buttner $\mathrm{U}$, Cohen B, Noth J, eds. Progress in Brain Research. Vol 64. Amsterdam: Elsevier Science Publishers, 1986:89-98.

30 Tarlov E. The postural effect of lesions of the vestibular nuclei: a note on species differences among primates. $J$ Neurosurg 1969;31:187-95.

31 Foltz EL, Knopp LM, Ward AA. Experimental spasmodic torticollis. J Neurosurg 1959;16:55-72.

32 Fukushima K, Takahashi J, Kudo J, Kato M. Interstitial-vestibular interaction in the control of head posture. Exp Brain Res 1985;57:264-70.

33 Fukushima KJ, Fukushima K, Tashiro K. Rigidity and dorsiflexion of the neck in progressive supranuclear palsy and the interstitial nucleus of Cajal. J Neurol Neurosurg Psychiatry 1987;50:1197-203. 